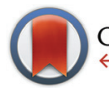

CrossMark

$\leftarrow$ click for updates

Cite this: Dalton Trans., 2015, 44

18727

Received 13th July 2015,

Accepted 1st October 2015

DOI: $10.1039 / c 5 d t 02651 b$

www.rsc.org/dalton

\section{Water stable triazolyl phosphonate MOFs: steep water uptake and facile regeneration $\uparrow$}

\author{
S. Begum, ${ }^{a, b}$ S. Horike, ${ }^{b}$ S. Kitagawa ${ }^{\star b, c}$ and H. Krautscheid ${ }^{\star a}$
}

The new microporous cobalt triazolyl phosphonate MOF ${ }_{\alpha}^{3}\left[\mathrm{CO}_{4} \mathrm{~L}_{3}\left(\mu_{3}-\mathrm{OH}\right)\left(\mathrm{H}_{2} \mathrm{O}\right)_{3}\right]\left(\mathrm{SO}_{4}\right)_{0.5} \cdot \mathrm{H}_{2} \mathrm{O} \quad\left(\mathrm{L}^{2-}=4-(4 \mathrm{H}-1,2,4\right.$-triazol4-yl)-phenyl phosphonate) exhibits exciting features including high water stability, reversible hydration-dehydration, steep water uptake in repeated cycles at low water vapor pressures and reactivation at room temperature under mild evacuation.

The design and development of water stable porous materials are crucial for industrial applications that require efficient capture and release of water such as solid desiccants, heat pumps and electric dehumidifiers. ${ }^{1-5}$ The well known solid sorption materials, i.e. silica gels and zeolites, are used on a large scale; however, with their limitations such as silica gels are not very energy efficient since most of the water sorption occurs outside their operating pressure windows, ${ }^{5}$ and zeolites require high temperature for regeneration. ${ }^{6}$ In contrast to pure inorganic porous materials, recently metal-organic frameworks have been recognized as alternative sorption materials for adsorptive heat transformation processes used in thermally driven adsorption chillers or adsorption heat pumps. ${ }^{2,5,7}$

In the last two decades MOFs have been extensively studied for their application in gas sorption and separation properties. $^{8}$ However, water sorption in MOFs remained underexplored as the majority of the reported MOFs are not stable in water. $^{9,10}$ One of the earliest water sorption studies in MOFs was reported in 2002 for HKUST-1 with the primary focus on evaluating stability rather than its sorption behavior. ${ }^{11}$ Until now most of the water sorption studies have focused on well

${ }^{a}$ Fakultät für Chemie und Mineralogie, Universität Leipzig, Johannisallee 29, Leipzig 04103, Germany. E-mail: krautscheid@rz.uni-leipzig.de; Fax: +0049-3419736199; Tel: $+0049-3419736172$

${ }^{b}$ Department of Synthetic Chemistry and Biological Chemistry, Graduate School of Engineering, Kyoto University, Katsura, Nishikyo-ku, Kyoto 615-8510, Japan. E-mail: kitagawa@icems.kyoto-u.ac.jp; Fax: +81-75-383-2732; Tel: +81-75-383-2733 ${ }^{c}$ Institute for Integrated Cell-Material Sciences (WPI-iCeMS), Kyoto University, Yoshida, Sakyo-ku, Kyoto 606-8501, Japan

$\dagger$ Electronic supplementary information (ESI) available. CCDC 1411211. For ESI and crystallographic data in CIF or other electronic format see DOI: 10.1039/ c5dt02651b known carboxylate based MOFs, i.e. HKUST-1, ${ }^{12,13}$ MIL-100/ $101,{ }^{2,14}$ MIL-53, CPO-27, UiO-66, ${ }^{12,15}$ MOF-801 and MOF-841. ${ }^{1}$ Although MOFs have attained special attention for water sorption properties in the last couple of years, it remains a challenge to find or design materials with higher water uptake in a narrow relative humidity range that resists hydrolysis and maintains high structural integrity.

In this regard a number of strategies have been reported to improve the water stability of MOFs. The MIL series and zirconium based UiO-series with tri- or tetravalent metal ions, respectively, are amongst the most stable poly-carboxylate MOFs. Other approaches include functionalization of organic linkers, i.e. incorporation of fluorinated linkers and use of longer alkyl side chains in order to enhance the hydrophobic character, and consideration of catenation in MOFs. ${ }^{10,16}$ These attempts increased the water stability but decreased the water uptake capacity due to enhanced hydrophobicity and reduction in surface areas.

In comparison with polycarboxylate MOFs, in spite of the known fact that phosphonate MOFs intrinsically impart remarkable hydrostability, ${ }^{17-19}$ CAU-14 is the only example of phosphonate MOFs recently reported for steep water uptake of $39.1 \mathrm{wt} \%$ at $p / p_{\mathrm{o}}=0.2 .{ }^{18}$ Therefore, the synthesis of new phosphonate MOFs with regular micropores for improved water sorption properties is of great interest. Furthermore, phosphonate MOFs exhibit a greater tendency for forming polar pores; this would allow a different selectivity than observed for nonpolar pores that are typical for the majority of carboxylate and imidazolate MOFs. $^{20}$

Herein, we report on a new porous water stable cobalt triazolyl phosphonate MOF ${ }_{\alpha}^{3}\left[\mathrm{Co}_{4} \mathbf{L}_{3}\left(\mu_{3}-\mathrm{OH}\right)\left(\mathrm{H}_{2} \mathrm{O}\right)_{3}\right]\left(\mathrm{SO}_{4}\right)_{0.5} \cdot x \mathrm{H}_{2} \mathrm{O}$ (1, $\mathbf{L}^{2-}=4-(4 H-1,2,4$-triazol-4-yl)phenyl phosphonate) with hydrophilic nanochannels. 1 exhibits excellent water stability and maintains its high structural integrity with water uptake already at low humidity and in a narrow relative humidity range. In contrast to zeolites, $\mathbf{1}$ demonstrates facile regeneration.

1 crystallizes in the hexagonal space group $P \overline{6} 2 c$ (no. 190) with a sixth of a formula unit $\left[\mathrm{Co}_{4} \mathbf{L}_{3}\left(\mu_{3}-\mathrm{OH}\right)\left(\mathrm{H}_{2} \mathrm{O}\right)_{3}\right]\left(\mathrm{SO}_{4}\right)_{0.5}$ in 
a)

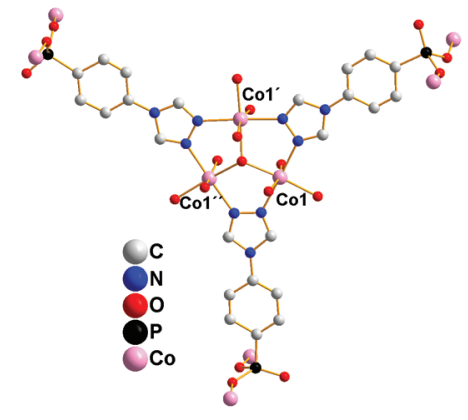

b)

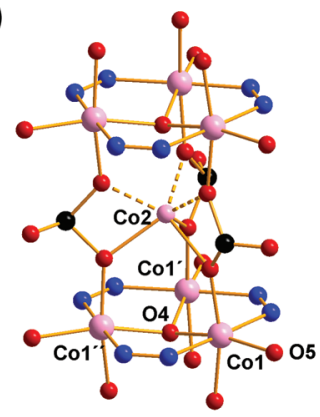

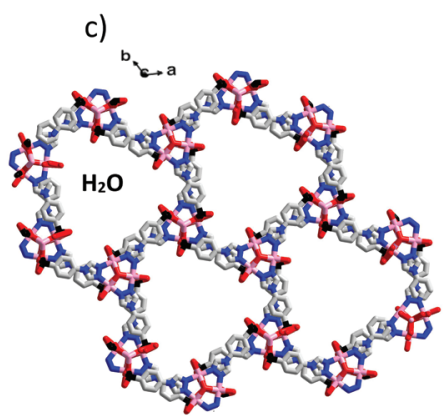

Fig. 1 Fragments of the crystal structure of 1: (a) coordination mode of the linker and trinuclear building unit with octahedral coordination of Co1; the bridging triazolyl phenyl groups and the $\mathrm{Co} 1$ and $\mathrm{P}$ atoms are coplanar; (b) connectivity between the $\mathrm{CO}_{3}\left(\mu_{3}-\mathrm{OH}\right)(\operatorname{trz})_{3}$ units; coordination of $\mathrm{Co} 2$ via phosphonate oxygen atoms (disorder not shown); (c) view along [001] showing the hexagonal arrangement of metal linker chains and the $1 \mathrm{D}$ pores; symmetry operations: ' $1-x+y, 1-x, z$; " $1-y, x-y, z$.

the asymmetric unit. $\$$ The charge balancing sulfate ion is disordered in the crystal structure of $\mathbf{1}$, which was identified by ion chromatography.

One of the two crystallographically independent $\mathrm{Co}^{2+}$ ions (Co1) and the $\mathrm{C}, \mathrm{N}$ and $\mathrm{P}$ atoms of the linker anion $\mathbf{L}^{2-}$ are coplanar (Fig. 1a). Two nitrogen atoms each of three triazole rings connect three cobalt ions to a typical $\mu_{3}-\mathrm{OH}$ and triazole bridged Co3 triangle (Fig. 1a). Such triangles are connected via three $\mathrm{O}-\mathrm{P}-\mathrm{O}$ units of phosphonate groups to linear stacks along [001] as shown in Fig. 1b.

In addition, $\pi \cdots \pi$ stacking interactions with $327 \mathrm{pm}(=c / 2)$ between the aromatic rings of the linker $\mathbf{L}^{2-}$ stabilize the crystal structure. With Co-O bond lengths from 206 to 210(1) pm, and Co-N bond lengths 212 and 215(1) pm, Co1 exhibits octahedral coordination. The centres of six trigonal prismatically arranged ${ }^{21}$ but disordered phosphonate oxygen atoms are occupied by the cobalt ions Co2 ( $\overline{6}$ position; Co2-O 219(1) pm, please see the ESI $\dagger$ ). Coordinated water molecules complete the octahedral coordination of $\mathrm{Co1}$, and non-coordinating phosphonate oxygen atoms protrude from each stack towards the interior of the 1D pores. Six such stacks connected via organic linkers result in hydrophilic hexagonal channels that retain physisorbed water molecules inside the pores. These channels are arranged like a hexagonal packing of rods and show a visible open diameter of $1.3 \mathrm{~nm}$.

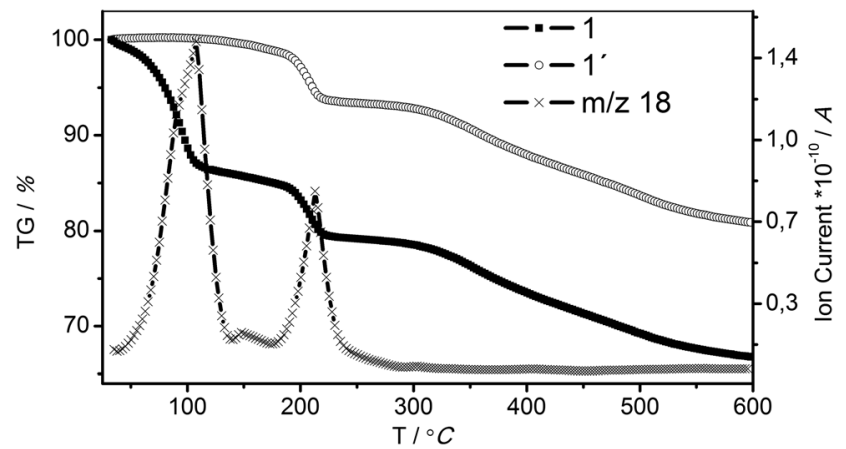

Fig. 2 TG-DTA curves of 1 (pristine), water molecules leave the structure in two steps confirmed by $m / z=18$ signals. $1^{\prime}$ is 1 after activation $\left(25^{\circ} \mathrm{C}, 1 \times 10^{-2} \mathrm{mbar}\right)$.

In order to evaluate the behavior of the coordinated and non-coordinated water molecules in the pores with temperature, TGA studies were performed (Fig. 2). The TGA curve of air dried 1 shows a mass loss of $20 \mathrm{wt} \%$ in two steps in the temperature range of 40 to $225^{\circ} \mathrm{C}$. These steps are attributed to the loss of non-coordinated and coordinated water molecules at about $90{ }^{\circ} \mathrm{C}$ and at $200{ }^{\circ} \mathrm{C}$, respectively. A mass loss of $19.4 \mathrm{wt} \%$ corresponds to 13 water molecules per formula unit. Under mild evacuation conditions $\left(25{ }^{\circ} \mathrm{C}, 1 \times 10^{-2}\right.$ mbar) only noncoordinated water molecules leave the framework ensured by the presence of the long plateau in the TGA curve of $\mathbf{1}^{\prime}$ ( $\mathbf{1}$ after activation at $\left.25{ }^{\circ} \mathrm{C}, 1 \times 10^{-2} \mathrm{mbar}\right)$ until the first mass loss of about $5.5 \%$ around $200{ }^{\circ} \mathrm{C}$. The experimental mass loss is consistent with the loss of three water molecules per formula unit (calc. 5.3\%). To test the framework hydro-stability, $\mathbf{1}$ was refluxed in water for 24 hours; the PXRD patterns confirm the stability of $\mathbf{1}$ in boiling water (Fig. S2 $\dagger$ ).

Recently we reported on a lanthanum MOF, $\left[\mathrm{La}_{3} \mathbf{L}_{4}\left(\mathrm{H}_{2} \mathrm{O}\right)_{6}\right]$ $\mathrm{Cl} \cdot \mathrm{xH}_{2} \mathrm{O}$ (2), with the same linker as 1 with a pore diameter of $1.9 \mathrm{~nm} .{ }^{17}$ Both compounds, 1 and 2 , exhibit a similar robust structural behavior and a steep water uptake (Fig. 3) at a relative water vapor pressure $p / p_{\mathrm{o}}=0.08$ and 0.21 for $\mathbf{1}$ (pore size $1.3 \mathrm{~nm}$ ) and 2 (pore size $1.9 \mathrm{~nm}$ ), respectively.

The volumetric water sorption isotherms for evacuated (at r.t.) samples of $\mathbf{1}$ and $\mathbf{2}$, denoted $\mathbf{1}^{\prime}$ and $\mathbf{2}^{\prime}$, were measured at

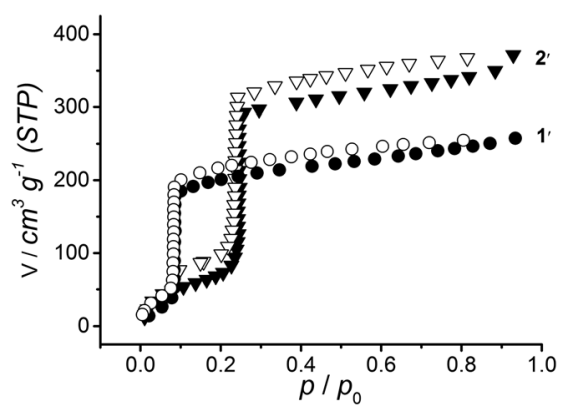

Fig. 3 Water sorption isotherms of $1^{\prime}$ (circle) and $2^{\prime}$ (triangle) at $25^{\circ} \mathrm{C}$. ( $1^{\prime}$ and $2^{\prime}$ are 1 and 2 activated at $25^{\circ} \mathrm{C}$ under $1 \times 10^{-2}$ mbar.) Solid and hollow symbols represent adsorption and desorption, respectively. 
$293 \mathrm{~K}$ and are shown in Fig. 3. Both, $\mathbf{1}^{\prime}$ and $\mathbf{2}^{\prime}$, exhibit sorption isotherms close to type I behavior, characterized by a small increase followed by a steep water uptake of 230 and $330 \mathrm{~cm}^{3}$ (STP) $\mathrm{g}^{-1}$ at low relative pressures and a long saturation plateau. $^{4,22}$ This behavior is similar to that observed in CPO-27 $(\mathrm{Ni}, \mathrm{Mg}, \mathrm{Co})^{10,23}$ as well as in zeolites. However, in CPO-27 water adsorption proceeds via chemisorption at coordinatively unsaturated metal sites followed by physisorption. CPO-27 MOFs retain their structural stability when thermally treated in the flow of $\mathrm{N}_{2}$, however, thermal treatment at temperatures higher than $100{ }^{\circ} \mathrm{C}$ in the presence of air leads to structural deformation. ${ }^{24} \mathrm{CPO}-27$ and 1 share the common feature of their honeycomb structure with a channel diameter of 1.1 and $1.3 \mathrm{~nm}$, respectively. In contrast to zeolites, in phosphonate MOFs 1 and 2, the most exciting and unique feature is their easy regeneration in 2 hours under mild evacuation conditions $\left(10^{-2} \mathrm{mbar}\right)$ at room temperature. $\mathbf{1}^{\prime}$ and 2 ' both show robust cycling performance as indicated by the reproducible water uptake in repeated cycles of adsorption and desorption shown in Fig. S7 and S8, $\uparrow$ respectively.

These promising results of steep water uptake capacity at low pressures in repeated cycles make $\mathbf{1}$ and $\mathbf{2}$ suitable hydrophilic adsorbents that require mild regeneration conditions with retention of their structural integrity. Adsorption profiles of abrupt water uptake in a single adsorption step as observed in 1 and 2 are rare in the literature, exhibited by very few other MOFs such as CAU-14, ${ }^{18} \mathrm{CAU}-10-\mathrm{H},{ }^{25} \mathrm{MIL}-125-\mathrm{NH} 2,{ }^{7} \mathrm{UiO}-67,{ }^{26}$ and In-MIL- $68,{ }^{5 b}$ at $p / p_{\text {o }}$ values of $0.2,0.2,0.2,0.58$ and 0.58 , respectively, in comparison with 0.08 for 1 and 0.21 for 2 . The absence of hysteresis loops in the sorption isotherms of $\mathbf{1}$ and 2 is an indicator of structural integrity in these phosphonate MOFs as well as continuous and reversible physisorption in a microporous material. The water stability of $\mathbf{1}$ and $\mathbf{2}$ arises from the bond strengths of phosphonate oxygen metal bonds and further from their extension in one dimensional metal phosphonate stacks connected via organic linkers. Furthermore, the presence of coordinated water protruding towards the $1 \mathrm{D}$ pores determines the hydrophilic nature of the pores and offers great affinity for the incoming guest water molecules during adsorption. Water uptake by $\mathbf{1}$ and 2 is found in the ideal pressure range for applications $\left(0.05<p / p_{\mathrm{o}}<0.4\right)$ and desorption temperatures at or below $80^{\circ} \mathrm{C}$. $^{2,3}$

Taking into account the second weight loss in the TGA curve of $\mathbf{1}$, we heated compound 1 at $130{ }^{\circ} \mathrm{C}$ under vacuum $\left(10^{-2} \mathrm{mbar}\right)$ in order to lose coordinated water molecules and generate unsaturated metal centers. We observed that 1 experiences a reversible color change from pink (pristine 1 and after activation at $25{ }^{\circ} \mathrm{C}$ under $10^{-2}$ mbar, denoted $1^{\prime}$ ) to dark purple (heated at $130{ }^{\circ} \mathrm{C}$ at $10^{-2}$ mbar or at $150{ }^{\circ} \mathrm{C}$ at ambient pressure, denoted 1", Fig. 4). PXRD patterns of 1" (Fig. S4†) retain lower angle peaks whereas at higher angles the peaks almost vanished. Crystals of 1 retained their shape but the crystallinity was no longer adequate for single crystal diffraction studies. Nevertheless, we studied $\mathbf{1}^{\prime \prime}$ for its water sorption behaviour. The water sorption isotherm of 1 " shown in Fig. 4 exhibits a significantly higher and gradual water uptake capacity compared to $\mathbf{1}^{\prime}$, probably due to structural rearrange-
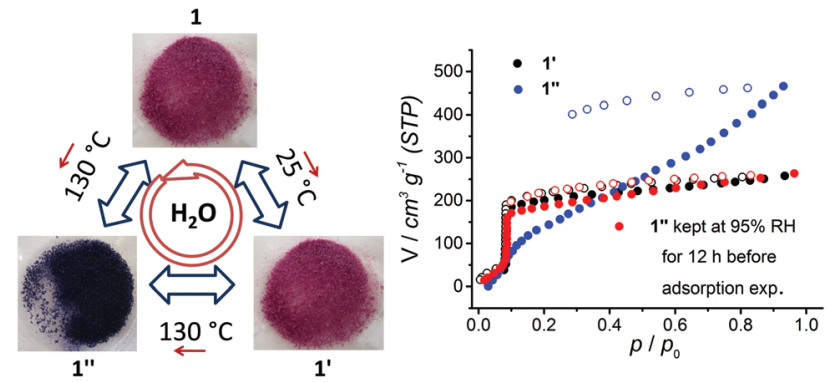

Fig. 4 Reversible transformation of 1 as a function of heating as well as humidity (left). Water sorption isotherm $\left(25^{\circ} \mathrm{C}\right)$ of $1^{\prime}, 1^{\prime \prime}$ and $1^{\prime \prime}$ after rehydration at $95 \% \mathrm{RH}$ at $90{ }^{\circ} \mathrm{C}$ for $12 \mathrm{~h}$ and activation at $25^{\circ} \mathrm{C}$ (right).

ment. Water is retained in $\mathbf{1}^{\prime \prime}$ as hysteresis is observed in adsorption and desorption cycles. In comparison with the steep water uptake in $\mathbf{1}^{\prime}, \mathbf{1}^{\prime \prime}$ shows gradual water uptake with almost doubled capacity. Samples of $\mathbf{1}^{\prime \prime}$ kept at 95\% RH for $12 \mathrm{~h}$ at $90{ }^{\circ} \mathrm{C}$ turned back from dark purple to pink. The PXRD pattern confirms that 1" changed back to 1. Furthermore, water sorption studies performed on the same sample confirmed reversible conversion of $\mathbf{1}^{\prime \prime}$ to $\mathbf{1}$ as the sorption isotherms of $\mathbf{1}^{\prime}$ and $\mathbf{1}^{\prime \prime}$, after keeping under $95 \% \mathrm{RH}$ at $90{ }^{\circ} \mathrm{C}$, exactly matched as shown in Fig. 4. We infer from these observations that $\mathbf{1}$ is highly stable under humid conditions, and as a function of temperature $\mathbf{1}$ can be transformed to $\mathbf{1}^{\prime}$ or $\mathbf{1}^{\prime \prime}$ and under humid conditions $\mathbf{1}^{\prime}$ and $\mathbf{1}^{\prime \prime}$ reversibly convert back to $\mathbf{1}$.

\section{Conclusions}

In conclusion, we introduced highly water stable triazolyl phosphonate MOFs, 1 and 2, as potentially efficient water sorption materials that exhibit steep water uptake in the ideal range for applications $\left(0.05<p / p_{\mathrm{o}}<0.4\right)$. Our studies confirm that 1 and 2 with hydrophilic nano-channels sustain their structure in boiling water as well as in saturated water vapors. After water sorption $\mathbf{1}$ and $\mathbf{2}$ can be activated under mild evacuation at room temperature and show reproducible water uptake in repeated cycles of adsorption and desorption. These results render porous triazolyl phosphonate MOFs interesting candidates for water sorption based applications such as adsorptive heat transformation processes.

\section{Acknowledgements}

We thank Dr J. Möllmer and U. Mikow (INC Leipzig) for support in the quantification of cobalt, sulphate and phosphate ions (AAS and ion chromatography). S. Begum acknowledges the graduate school BuildMoNa and Research Academy Leipzig (RAL) for supporting her research visit at Kyoto University. She extends her acknowledgement for financial support by the Higher Education Commission, Pakistan and a fellowship from DAAD. Financial support from Deutsche Forschungsgemeinschaft (SPP 1362 - Poröse Metall-organische 
Gerüstverbindungen) and Universität Leipzig (PbF-1) is gratefully acknowledged.

\section{Notes and references}

\$Crystal data: $1\left(\mathrm{C}_{24} \mathrm{H}_{49} \mathrm{~N}_{9} \mathrm{Co}_{4} \mathrm{O}_{27} \mathrm{P}_{3} \mathrm{~S}_{0.5}\right)$ : Stoe IPDS-2 $\mathrm{T}$ Diffractometer, $M_{\mathrm{m}}=$ $1240.38 \mathrm{~g} \mathrm{~mol}^{-1}$, crystal size $0.30 \times 0.05 \times 0.05 \mathrm{~mm}^{3}$, hexagonal, space group $P \overline{6} 2 c$ (no. 190) $a=2059.40(16), c=653.04(4), Z=2, T=180(2) \mathrm{K}, V=2398.6(4) \times$ $10^{6} \mathrm{pm}^{3}, d_{\text {calc }}=1.717 \mathrm{~g} \mathrm{~cm}^{-3}, \mu=1.576 \mathrm{~mm}^{-1}, \lambda=71.073 \mathrm{pm}\left(\mathrm{Mo}-\mathrm{K}_{\alpha}\right)$, 5525 measured, 1465 independent reflections, $R_{\text {int }}=0.0713,1176$ with $I>2 \sigma(I)$, 100 parameters, phosphonate oxygen atoms, coordinated water and the $\mu_{3}-\mathrm{OH}$ group are disordered (please see the ESI for details), $\mathrm{H}$ atoms of phosphonate ligands in idealized positions. Since the sulfate anion and water molecules are disordered in the pores the SQUEEZE ${ }^{27}$ routine was applied. $R_{1}$ (observed reflections $)=0.0540, w R_{2}$ (all data) $=0.1416$, absolute structure parameter $=0.47(7)$; max. and min. residual electron density peaks 0.6 and $-1.3 \mathrm{e}^{-} / 10^{6} \mathrm{pm}^{3}$. CCDC 1411211 contains the supplementary crystallographic data for this paper.

1 H. Furukawa, F. Gándara, Y. B. Zhang, J. Jiang, W. L. Queen, M. R. Hudson and O. M. Yaghi, J. Am. Chem. Soc., 2014, 136, 4369.

2 F. Jeremias, A. Khutia, S. K. Henninger and C. Janiak, J. Mater. Chem., 2012, 22, 10148.

3 A. Khutia, H. U. Rammelberg, T. Schmidt, S. Henninger and C. Janiak, Chem. Mater., 2013, 25, 790.

4 N. C. Burtch, H. Jasuja and K. S. Walton, Chem. Rev., 2014, 114, 10575.

5 (a) J. Canivet, A. Fateeva, Y. Guo, B. Coasne and D. Farrusseng, Chem. Soc. Rev., 2014, 43, 5594; (b) J. Canivet, J. Bonnefoy, C. Daniel, A. Legrand, B. Coasne and D. Farrusseng, New J. Chem., 2014, 38, 3102.

6 (a) P. L. Llewellyn, F. Schüth, Y. Grillet, F. Rouquerol, J. Rouquerol and K. K. Unger, Langmuir, 1995, 11, 574; (b) R. Gopal, B. R. Hollebone, C. H. Langford and R. A. Shigeishi, Sol. Energy, 1982, 28, 421; (c) O. M. Dzhigit, A. V. Kiselev, K. N. Mikos, G. G. Muttik and T. A. Rahmanova, Trans. Faraday Soc., 1971, 67, 458; (d) M. D. Olga, V. K. Andrie, A. R. Tamara and S. P. Zhdanov, J. Chem. Soc., Faraday Trans., 1979, 75, 2662; (e) S. T. Wilson, B. M. Lok, C. A. Messina, T. R. Cannan and E. M. Flanigen, J. Am. Chem. Soc., 1982, 104, 1146; (f) X. Benjing, Z. Chenxi and Y. Zifeng, J. Nat. Gas Chem., 2005, 14, 65; (g) S. Komarneni, R. Pidugu and V. C. Menon, J. Porous Mater., 1996, 3, 99.

7 F. Jeremias, D. Fröhlich, C. Janiak and S. K. Henninger, New J. Chem., 2014, 38, 1846.

8 (a) D. Lässig, J. Lincke, J. Moellmer, C. Reichenbach, A. Moeller, R. Gläser, G. Kalies, K. A. Cychosz, M. Thommes, R. Staudt and H. Krautscheid, Angew. Chem., Int. Ed., 2011, 50, 10344; (b) S. Ma, Pure Appl. Chem., 2009, 81, 2235; (c) J. Liu, P. K. Thallapally, B. P. McGrail, D. R. Brown and J. Liu, Chem. Soc. Rev., 2012, 41, 2308; (d) J. R. Li, R. J. Kuppler and H. C. Zhou, Chem. Soc. Rev., 2009, 38, 1477; (e) N. Nijem, H. Wu, P. Canepa, A. Marti, K. J. Balkus, T. Thonhauser, J. Li and Y. J. Chabal, J. Am. Chem. Soc., 2012, 134, 15201; $(f)$ J. Moellmer, A. Moeller, C. Patzschke, K. Stein, D. Lässig, J. Lincke, R. Gläser,
H. Krautscheid and R. Staudt, J. Mater. Chem., 2012, 22, 10274.

9 (a) T. L. Kinnibrugh, A. A. Ayi, V. I. Bakhmutov, J. Zoń and A. Clearfield, Cryst. Growth Des., 2013, 13, 2973; (b) J. E. Mondloch, M. J. Katz, N. Planas, D. Semrouni, L. Gagliardi, J. T. Hupp and O. K. Farha, Chem. Commun., 2014, 50, 8944.

10 K. Tan, N. Nijem, Y. Gao, S. Zuluaga, J. Li, T. Thonhauser and Y. J. Chabal, CrystEngComm, 2014, 17, 247.

11 Q. Min Wang, D. Shen, M. Bülow, M. Ling Lau, S. Deng, F. R. Fitch, N. O. Lemcoff and J. Semanscin, Microporous Mesoporous Mater., 2002, 55, 217.

12 J. B. DeCoste, G. W. Peterson, B. J. Schindler, K. L. Killops, M. A. Browe and J. J. Mahle, J. Mater. Chem. A, 2013, 1, 11922.

13 L. Grajciar, O. Bludský and P. Nachtigall, J. Phys. Chem. Lett., 2010, 1, 3354-3359.

14 G. Akiyama, R. Matsuda, H. Sato, A. Hori, M. Takata and S. Kitagawa, Microporous Mesoporous Mater., 2012, 157, 89.

15 P. Ghosh, Y. J. Colón and R. Q. Snurr, Chem. Commun., 2014, 50, 11329.

16 H. Jasuja and K. S. Walton, Dalton Trans., 2013, 42, 15421.

17 S. Begum, Z. Wang, A. Donnadio, F. Costantino, M. Casciola, R. Valiullin, C. Chmelik, M. Bertmer, J. Kärger, J. Haase and H. Krautscheid, Chem. - Eur. J., 2014, 20, 8862.

18 N. Hermer and N. Stock, Dalton Trans., 2015, 44, 3720.

19 (a) M. Taddei, F. Costantino, F. Marmottini, A. Comotti, P. Sozzani and R. Vivani, Chem. Commun., 2014, 50, 14831; (b) S. F. Tang, J. J. Cai, L. J. Li, X. X. Lv, C. Wang and X. B. Zhao, Dalton Trans., 2014, 43, 5970; (c) J. M. Taylor, K. W. Dawson and G. K. H. Shimizu, J. Am. Chem. Soc., 2013, 135, 1193.

20 S. Paranthaman, F. X. Coudert and A. H. Fuchs, Phys. Chem. Chem. Phys., 2010, 12, 8123.

21 (a) O. Gourdon, V. Petricek, M. Dusek, P. Bezdicka, S. Durovic, D. Gyepesova and M. Evain, Acta Crystallogr., Sect. B: Struct. Sci., 1999, 55, 841; (b) S. A. Kubow, K. J. Takeuchi, J. J. Grzybowski, A. J. Jircitano and V. L. Geodken, Inorg. Chim. Acta, 1996, 241, 21; (c) C. Wendelstorf and R. Kraemer, Angew. Chem., Int. Ed. Engl., 1997, 36, 2791; (d) H. A. Sagher, I. Fallis, L. J. Farrugia and R. D. Peacock, J. Chem. Soc., Chem. Commun., 1993, 1499.

22 K. S. W. Sing, D. H. Everett, R. A. W. Haul, L. Moscou, R. A. Pierotti, J. Rouquerol and T. Siemieniewska, Pure Appl. Chem., 1985, 57, 603.

23 A. Das, P. D. Southon, M. Zhao, C. J. Kepert, A. T. Harris and D. M. D. Alessandro, Dalton Trans., 2012, 41, 11739.

24 P. D. C. Dietzel, B. Panella, M. Hirscher, R. Blom and H. Fjellvåg, Chem. Commun., 2006, 959.

25 D. Fröhlich, S. K. Henninger and C. Janiak, Dalton Trans., 2014, 43, 15300.

26 N. Ko, J. Hong, S. Sung, K. E. Cordova, H. J. Park, J. K. Yang and J. Kim, Dalton Trans., 2015, 44, 2047.

27 PLATON; A. L. Spek, J. Appl. Crystallogr., 2003, 36, 7. 